\title{
NITRIDING OF NIMONIC 80 A ALLOY FOR IMPROVING CAVITATION EROSION RESISTANCE
}

\author{
Cosmin Ion BELIN, Ion MITELEA, llare BORDEAŞU, Ion Dragos UTU, \\ Corneliu Marius CRĂCIUNESCU
}

\begin{abstract}
Politehnica University of Timisoara, Timisoara, Romania, EU, cosmin.belin@student.upt.ro, ion.mitelea@upt.ro, ilare.bordeasu@upt.ro, dragos.utu@upt.ro, corneliu.craciunescu@upt.ro
\end{abstract}

https://doi.org/10.37904/metal.2021.4218

\begin{abstract}
The paper studies the improvement of cavitation erosion resistance for Nimonic $80 \mathrm{~A}$ alloy whose surface has been subjected to nitriding. The cavitation erosion tests were performed with an ultrasonic vibrating device in accordance to ASTM G32-2010. The cavitated samples were further investigated by optical and scanning electron microscopy. The analysis of the cavitation curves showed 8.65 times decrease in mass loss and 8 times increase in cavitation erosion resistance of nitrided samples compared to those in solution treatment state.
\end{abstract}

Keywords: Nimonic 80A alloy, nitriding, cavitation erosion

\section{INTRODUCTION}

Cavitation is the process of formation, growth and implosion of bubbles containing vapors, gases or a mixture of gas vapors due to cyclic pressure changes in the flowing liquid [1]. Cavitation implosion is an effect of changing the pressure from the low-value zone to a high pressure region, causing condensation of vapors that fill the cavity bubbles. The implosion phenomenon occurs at a very high speed (exceeding $100 \mathrm{~m} / \mathrm{s}$ ), and the growth and degradation time of the cavitation bubble is in the order of milliseconds [1-3]. The dynamics of bubble formation and collapse is dependent on the physico-chemical properties of the fluid and the distance between the wall and the bubble interaction site. In the vicinity of the wall, an implosion of bubbles is formed, which can reach speeds of 300 to $500 \mathrm{~m} / \mathrm{s}$. Microcurrents formed during cavitation bubble impulse transmit pressure walls to the walls of the order of $1 \div 4 \mathrm{GPa}[4,5]$. The multiple repetition of the cavitation implosion causes the destruction of the material.

In order to improve the resistance to various forms of wear, including cavitation erosion, research efforts are focused on the application of volume or surface heat treatments, as well as techniques for physical surface modification (local remelting, welding loading, CVD deposits or PVD, mechanical laser beam hardening, etc.) [6-9].

The present contribution investigates the response to cavitation erosion of nickel-based alloy parts subjected to surface hardening by applying thermochemical nitriding treatment.

\section{INVESTIGATED MATERIAL, EXPERIMENTAL STAND AND WORKING PROCEDURE}

From cylindrical bars, $\varnothing 20 \times 300 \mathrm{~mm}$, solution treatment $\left(1080^{\circ} \mathrm{C} / 8 \mathrm{~h} /\right.$ air) cavitation samples were made which subsequently were treated by plasma nitriding at $530^{\circ} \mathrm{C}$ for $16 \mathrm{~h}$.

Cavitation tests were performed on a vibrator device with piezoceramic crystals, which complies with standard ASTM G32 - 2016 requirements (see the principle diagram of Figure 1) [6]. The functional parameters 
determining cavitation erosion intensity are: $50 \mu \mathrm{m}$ vibration double vibration, $20000 \pm 2 \% \mathrm{~Hz}$ frequency and $22^{\circ} \mathrm{C}\left(1^{\circ} \mathrm{C}\right)$ cavitating liquid temperature (double distilled water).

The tests were performed with variable durations consisting of 12 periods of a total of 165 minutes. The intermediate periods were 5 minutes, 10 minutes and the other 10 for 15 minutes.

At the beginning of the test, the samples were washed in acetone, dried in a hot air stream and weighed with analytical balance that can weigh the mass with an accuracy of five decimals. After each period of cavitation the samples underwent the same process.

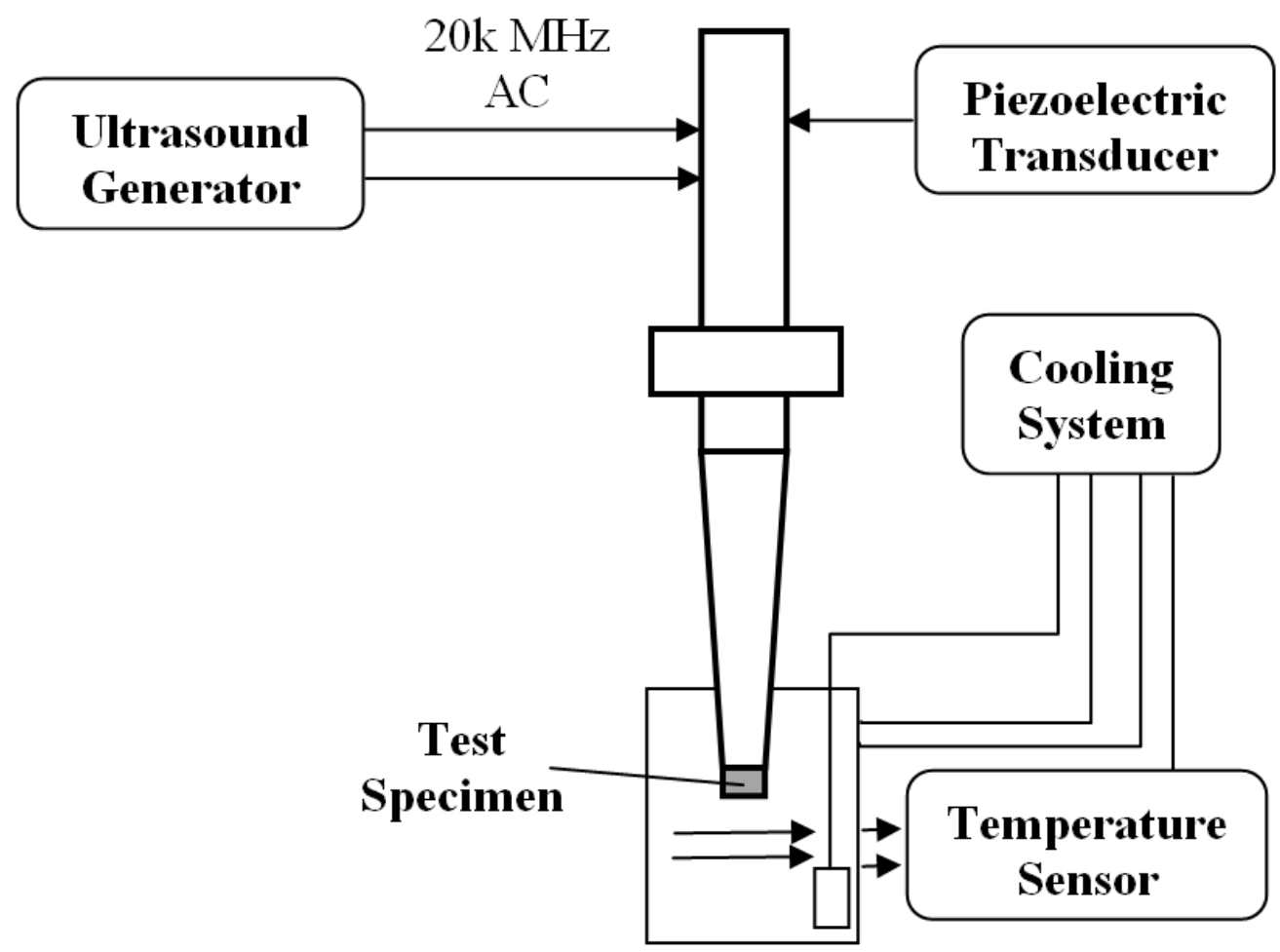

Figure 1 Details about the ultrasonic equipment used in the cavitation erosion experiments

In order to track the evolution of the degradation, before testing and at the end of each period the exposed surfaces of the samples were photographed with the high resolution camera Fujifilm S2750 and were examined under optical microscope.

The weighed mass loss of each intermediate period " $\mathrm{i}$ ", determined the corresponding mass loss, mi.

In order to determine the total eroded mass the following equation was used $m i=\sum_{i=1}^{12} \Delta m i$, where $m i$ eroded mass $(\mathrm{mg})$. Based on the mass losses, the erosion rate values were determined.

\section{RESULTS AND DISCUSSIONS}

\subsection{Cavitation curves}

Figures 2 and 3 show the variation curves of mass losses and erosion rate with attack time. Both graphs highlight the favourable effect of nitriding treatment on cavitation wear resistance. Thus, after a period of cavitation attack of $165 \mathrm{~min}$. there is a decrease in material losses from $51.5 \mathrm{mg}$ (characteristic of solution treatment) to $5.95 \mathrm{mg}$ (characteristic of nitriding treatment). At the same time, the erosion rate during the 
stabilization period decreases from approx. $0.40 \mathrm{mg} / \mathrm{min}$. the approx. $0.05 \mathrm{mg} / \mathrm{min}$. It is also worth noting that both mass losses and erosion rates remain constant throughout the cavition attack.

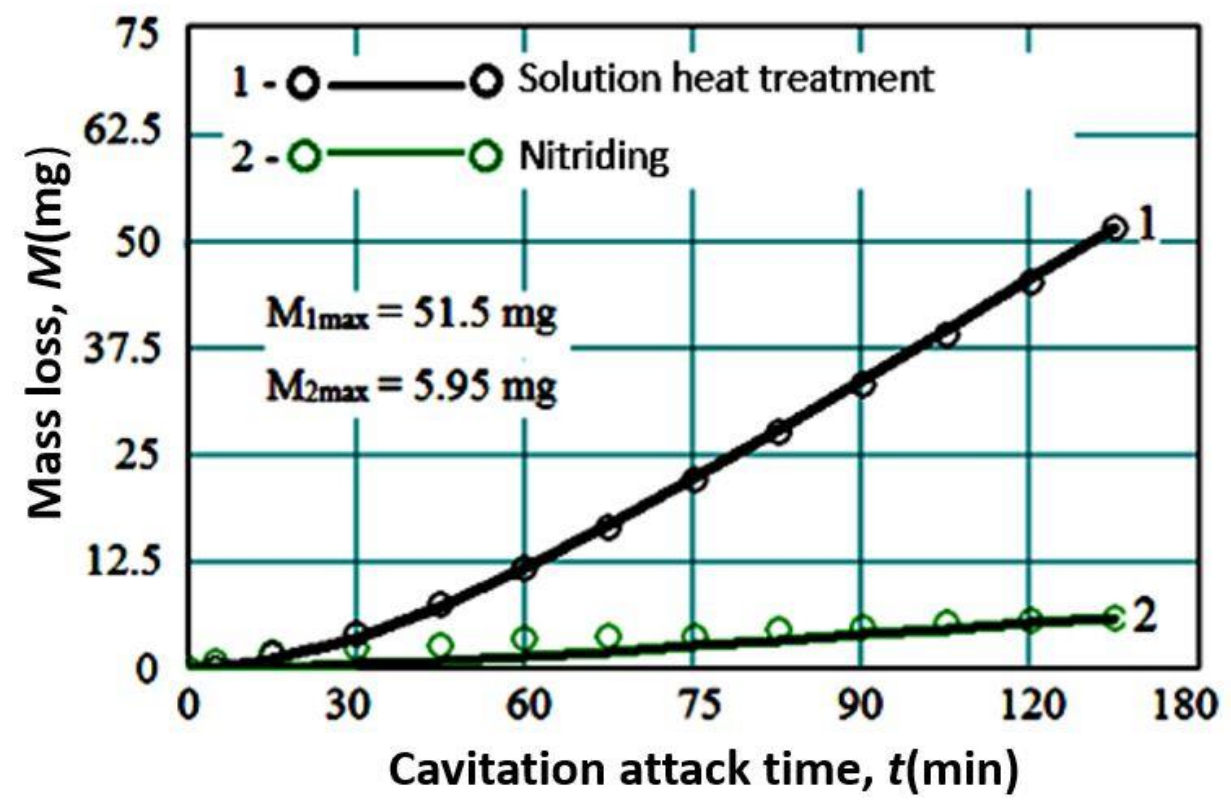

Figure 2 Evolution of mass loss with attack time

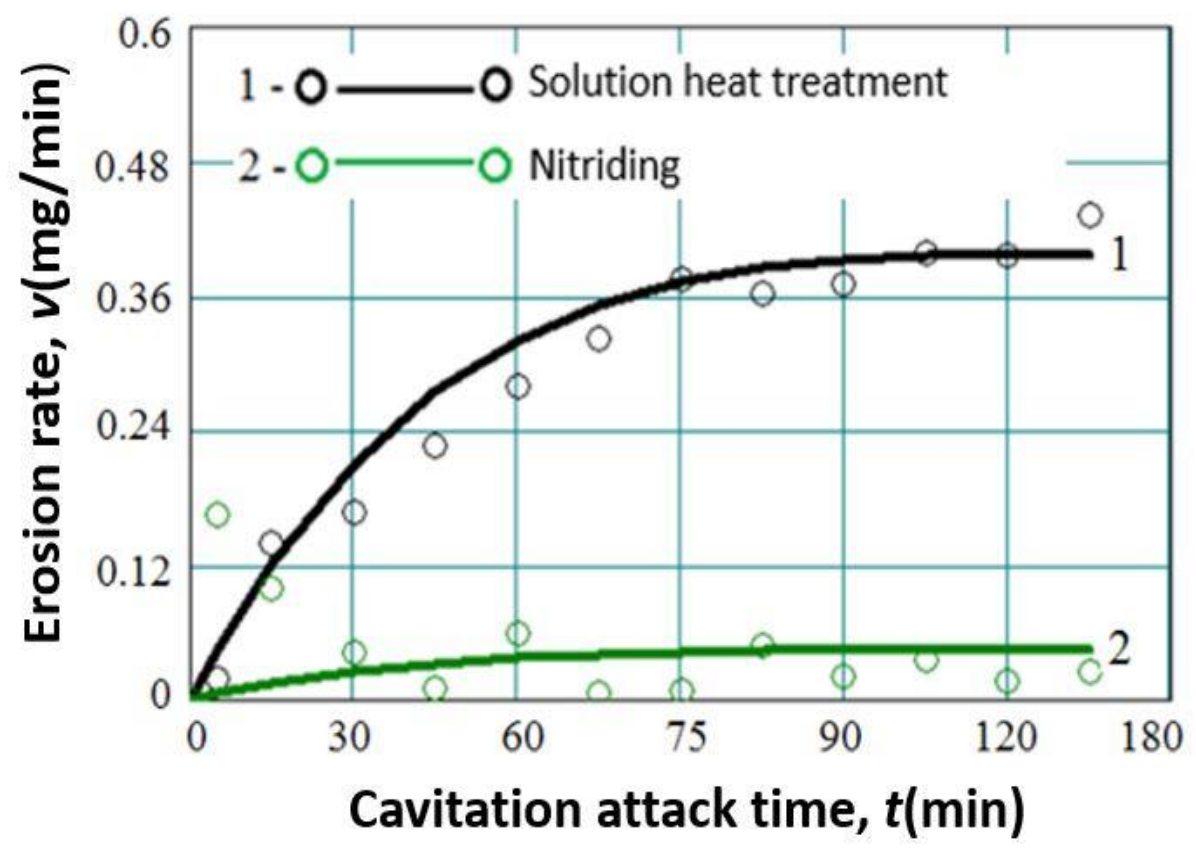

Figure 3 Cavitation erosion rate with attack time

\subsection{Macro - and micrographic examinations}

Figure 4 shows the macroscopic appearance of the sample surface after each cavitation test period. 


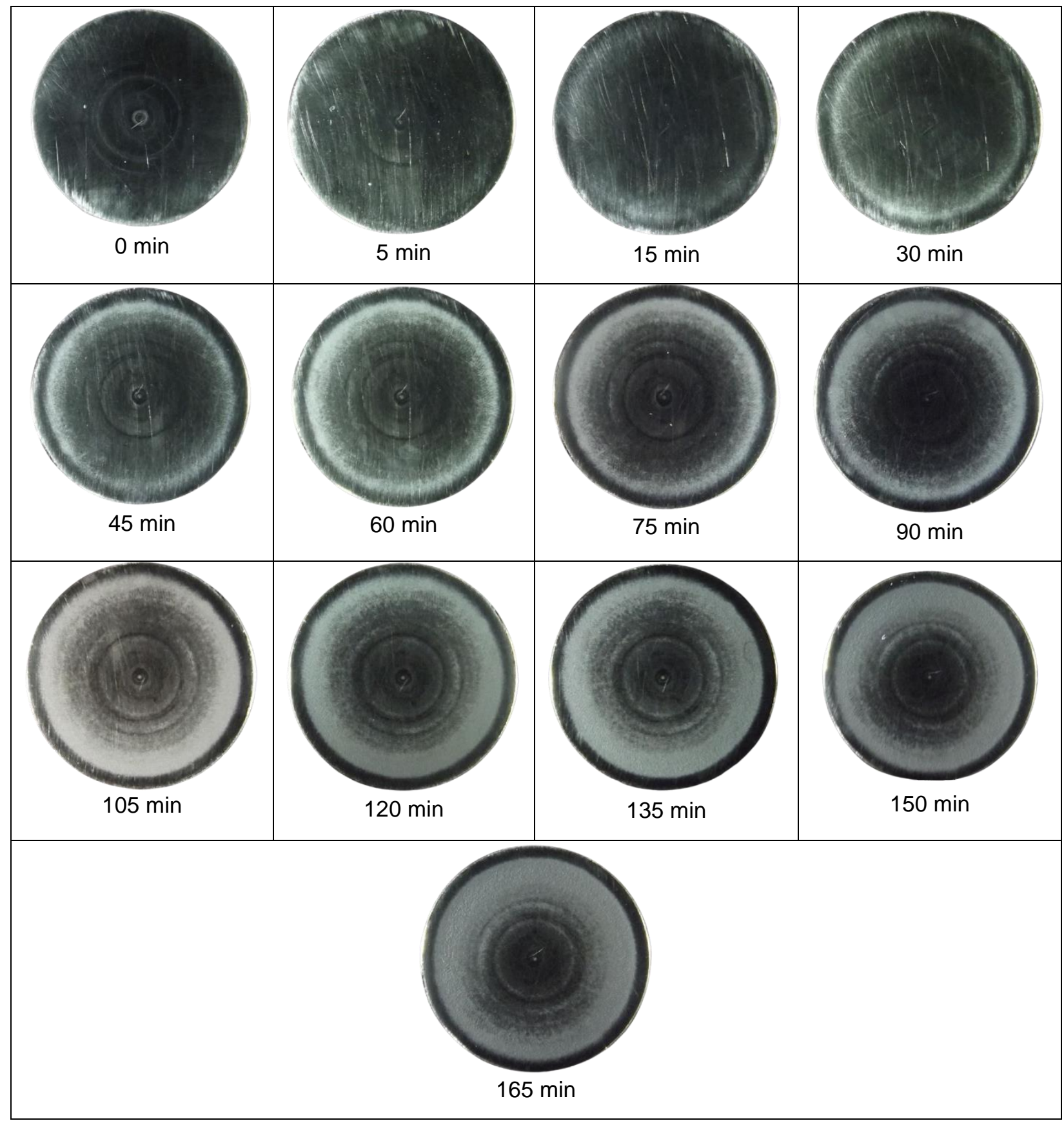

Figure 4 Macrographic images of the surface of nitrided samples, tested at variable cavitation time

If in the first 15-30 min cavition attack does not reveals an initiation of the surface degradation phenomenon, at longer durations the appearance of concentric rings is observed which become more powerful after 90 minutes and which practically keeps the same morphology until the end of the test.

Another aspect of the high resistance to cavitation is the lack of caverns arranged stellarly towards the periphery, as it appears in materials with lower hardness.

Examination with a scanning electron microscope (SEM) of the topography of the cavitated surfaces (Figure 5) proves that the removal mechanisms of the material, during cavitation erosion, are controlled by a process of plastic deformation, accompanied by the formation of sliding steps, characteristic of the $y$ matrix which has a 
fcc crystal lattice. The pinches present in the eroded surface, especially on the limits of the grains of solid solution $y$ are the places of the former nitride particles of the alloying elements. Increasing the nitrogen content in the surface layer increases the elastic energy returned to the cavitational medium and decreases the amount of plastic energy absorbed by the alloy at the points of cavitational impact.

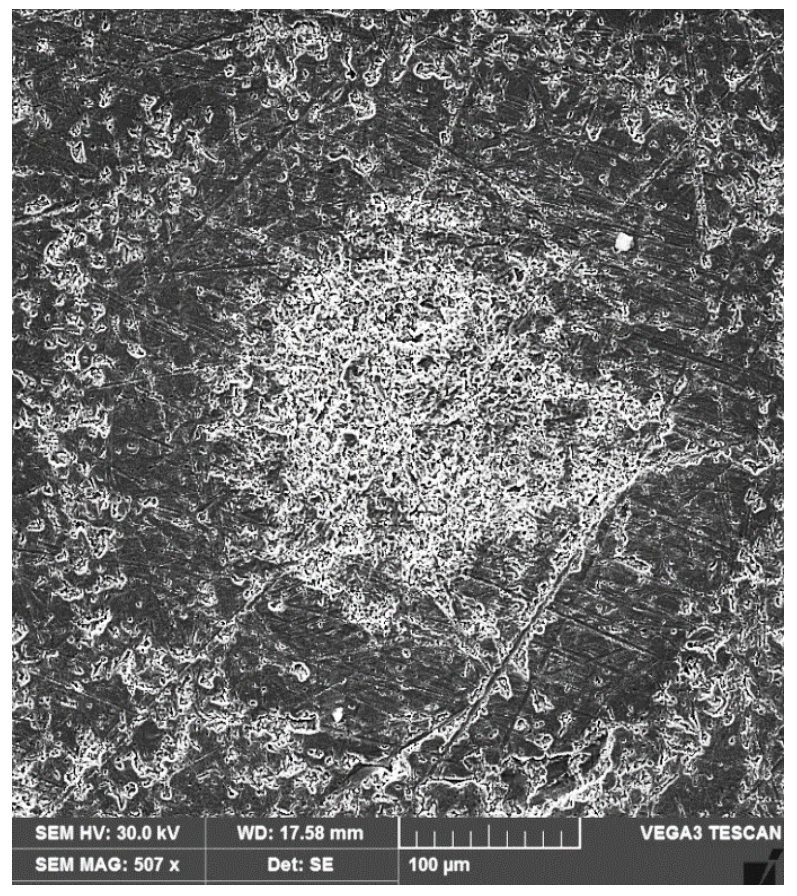

$-a-$

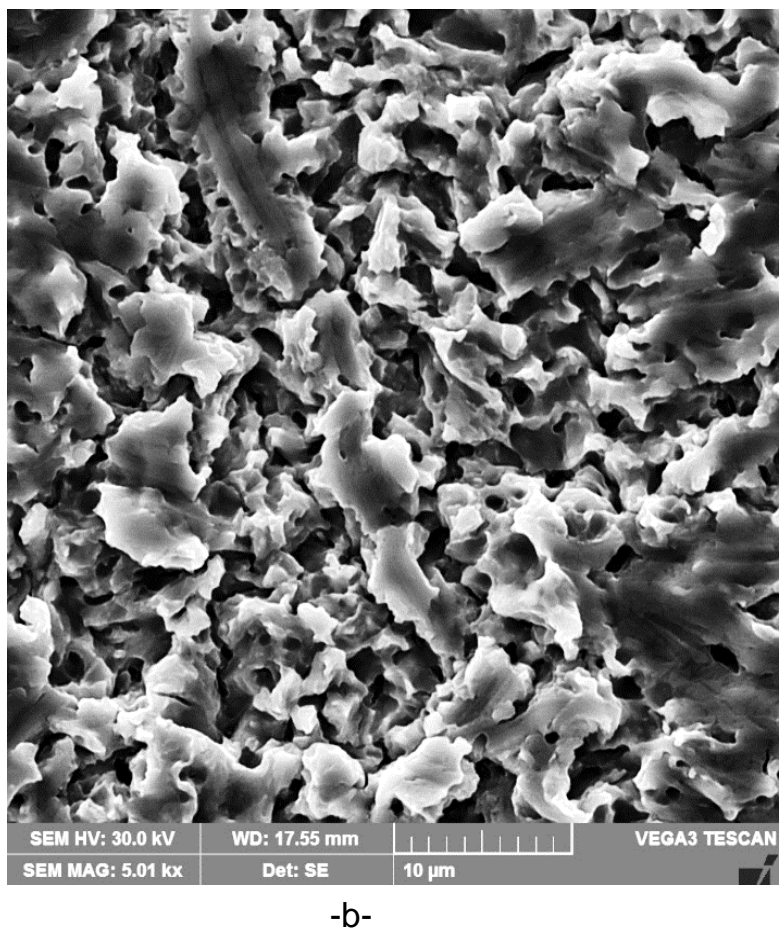

$-b-$

Figure 5 Detector SE micrograph (Tesca Vega SEM) of the nitrided surface after the cavity attack for $165 \mathrm{~min}$

\section{CONCLUSIONS}

Compared to the solution treatment, enrichment the surface of the parts by applying plasma nitriding at 530 ${ }^{\circ} \mathrm{C}$ leads to the reduction of mass losses of approx. 8.65 times and the erosion rate through cavitation of approx. 8 times.

As a result of the fatigue processes and the plastic deformation effects that appeared, micro-cracks were initiated and developed in the triple contact points on the limits of the $y$ solid solution grains.

\section{REFERENCES}

[1] FRANK, J.-P., MICHEL, J.M. Fundamentals of cavitation. Kluwer Academic Publishers-Dordrecht/Boston/London, 2004.

[2] NIEDERHOFER, P., HUTH, S. Cavitation erosion resistance of high interstitial CrMnCN austenitic stainless steels. Wear. 2013, vol. 301, iss. 1-2, pp. 457- 466.

[3] NEDELCU, D, NEDELONI, M. D., LUPINCA, C.I. Cavitation erosion research on the X3CrNi13-4 stainless steel. Materials Science Forum. [online]. 2016, vol. 782, pp. 263-268. Available from: https://doi.org/10.4028/www.scientific.net/MSF.782.263.

[4] KRELLA, A.K., KRUPA, A. Effect of cavitation intensity on degradation of X6CrNiTi18-10 stainless steel. Wear. 2018, vol. 408-409, pp. 180-189. 
[5] BELIN, C., MITELEA, I., BORDEASU, I., CRACIUNESCU, C.M. On surface topography and microstructure in cavitation erosion tests of alloy 80 A. IOP Conf. Series: Materials Science and Engineering. [online]. 2018, vol. 416, 012010. Available from: https://doi.org/10.1088/1757-899X/416/1/012010.

[6] Standard method of vibratory cavitation erosion test. ASTM, Standard G32-2016

[7] ALABEEDI, K.F., ABBOUD, J.H., BENYOUNIS, K.Y. Microstructure and erosion resistance enhancement of nodular cast iron by laser melting. Wear. 2009, vol. 266, pp. 925-933.

[8] LO, K.H., KWOK C.T., WANG, K.Y., AI WENJI. Implications of solution treatment on cavitation erosion and corrosion resistances and synergism of austenitic stainless steel. Wear. 2017, vol. 392-393, pp. 159-166.

[9] HU, H.X., GUO, X.M., ZHENG Y. Comparison of the cavitation erosion and slurry erosion behavior of cobaltbased and nickel-based coatings. Wear. 2019, vol. 428-429, pp. 246-257. 